\title{
Criação, destruição e realocação de empregos em países selecionados: uma meta-análise
}

Ricardo Schmidt Filho Professor do Departamento de Economia e Finanças da UFCG.

Luiz Alberto Esteves Professor do Programa de Pós-Graduaçāo em Políticas Públicas da UFPR e pesquisador do CNPq.

Mauricio Bittencourt Professor do Programa de Pós-Graduação em Desenvolvimento Econômico da UFPR.

\section{Palavras-chave}

Emprego, rotatividade, meta-análise.

Classificação JEL J21, J63, C83.

\section{Keywords}

Employment; Turnover; Metaanalysis.

JEL Classification J21, J63, C83.

\section{Resumo}

$\mathrm{O}$ artigo realiza uma meta-análise para fluxos de empregos com base em informaçóes de 62 artigos científicos referente a 35 países para o período de 1963 a 2007. O artigo apresenta os fatos estilizados da literatura e fornece os seguintes resultados empíricos: 1) o setor industrial destrói mais empregos e cria menos empregos do que a economia como um todo; 2) os mercados de trabalho tornaram-se mais flexíveis com o passar das décadas; 3 ) os países da Civil Law têm taxas de criação e de variação líquida superiores aos países da Commom Law, que, por sua vez, apresentaram taxa de destruiçáo superior; 4) os países Emergentes exibiram taxas superiores em todos os fluxos quando comparados aos países da OCDE e às economias Em Transição; 5) países em desenvolvimento apresentam criação de empregos maior que os desenvolvidos; e 6) quanto maior o crescimento e quanto maior a abertura da economia, maior será a criaçáo líquida de empregos, uma vez que a destruição se torna menor..

\section{Albstract}

This paper uses meta-analysis to investigate job flows among 62 studies for 35 countries for the 1963-2007 period. The article presents the stylized facts of the literature and provides the following empirical results: 1) the industrial sector destroys more jobs and creates fewer jobs than the rest of the economy; 2) the labor markets became less flexible over time, with larger job flows after every decade; 3) the Civil Law countries have rates of job creation and net job variation higher than those Common Law countries whose rate of job destruction is higher; 4) the emerging countries presented higher rates for all flows analyzed when compared to the OECD countries and to the transition economies; 5) the developing countries showed higher rates of job creation than the developed ones; and 6) the larger the economic growth and market opening, the higher is the net rate of job creation, since the job destruction is smaller. 


\section{1_Introdução}

Este artigo trata de uma meta-análise que visa à compreensão de aspectos atrelados à literatura sobre fluxos de emprego. A virtude de uma meta-análise é a possibilidade de verificação de quais os impactos de variáveis como o tipo de legislação trabalhista, o grau de abertura da economia, o crescimento econômico, o nível de investimento, o nível de desenvolvimento, os setores econômicos e o período temporal (décadas) sobre os fluxos de emprego.

A análise dessas questóes não pode ser realizada quando o objeto de estudo é apenas um país, uma vez que, dentro desse, não se pode avaliar, por exemplo, a diferença de origem legal da legislação trabalhista ou a diferença de desenvolvimento entre países, sendo que a meta-análise possibilita esse tipo de estudo.

Com esse objetivo, foram coletados dados de 62 artigos científicos, ${ }^{1}$ totalizando 35 países que cobrem um horizonte temporal de 1963 até 2007, e, com base nesses dados e em outros coletados no Banco Mundial ${ }^{2}$ e no Centro de Comparaçóes Internacionais de Produçáo, Preços e Renda da Universidade da Pensilvânia, ${ }^{3}$ partiu-se para a realização da meta-análise.

Procurou-se analisar como os fluxos de emprego se comportaram ao longo das décadas analisadas $(1970,1980,1990 \mathrm{e}$
2000), no intuito de verificar se os mercados se tornaram mais flexíveis durante o período analisado, tendo em vista o advento de políticas mais liberais em praticamente todo o globo. Outro aspecto da análise é o efeito da origem legal da legislação trabalhista ${ }^{4}$ (Civil Law e Common Law) nos fluxos de emprego.

Outro ponto é a comparação entre os resultados dos trabalhos que se destinam apenas à indústria em relação aos trabalhos que avaliam todos os setores, já que o intuito é a verificação do fato estilizado de que a indústria cria menos e destrói mais empregos que o setor de serviços.

Também é observada a distinção entre o grau de desenvolvimento entre os países, visto que a literatura e os fatos estilizados indicam que os países em desenvolvimento apresentam fluxos mais
${ }^{1} \mathrm{O}$ Anexo A, ao final do trabalho, relaciona todos os trabalhos consultados, bem como as respectivas referências bibliográficas.

${ }^{2}$ www.bancomundial.org.br.

${ }^{3}$ http://pwt.econ.upenn.edu/.

${ }^{4}$ Para mais detalhes e compreensão dessas formas balizadoras da legislação, ver Botero et al (2004). O efeito da legisha. gislaçáo pode ser considerado como um efeito fixo, uma vez que é o modelo no qual as leis de um país são constituídas, não podendo assim variar, impactam nos fluxos de trabalho, ou seja, se países da Common Law, origem jurídica mais flexível que a Civil Law, apresentam maior realocação e movimentação no mercado de trabalho. 
elevados que os países desenvolvidos. $\mathrm{Pa}$ ra enfatizar melhor essa questáo, os países foram organizados em três grupos - OCDE, Emergentes e Em Transição -, e assim observadas a dinâmica dos fluxos entre os blocos.

Por fim, são avaliados dois aspectos presentes em vários artigos dessa literatura: como o crescimento econômico impacta nos fluxos e de que forma o grau de abertura ${ }^{5}$ traz impactos sobre a dinâmica de emprego.

Este artigo é composto de três seções, além desta introdução. Na seção 2, parte-se para a discussáo dos principais fatos estilizados e definiçoóes sobre o tema. Na seção 3, são discutidos os aspectos metodológicos, os dados utilizados e os principais resultados encontrados.

${ }^{5}$ Aqui considerado o somatório do \% de exportaçóes e importaçóes em relação ao PIB.

${ }^{6}$ Esta elevada rotatividade traz consigo efeitos positivos e negativos. Os aspectos positivos são associados à possibilidade de rápida adaptação às mudanças tecnológicas, fato essencial para o crescimento econômico nos dias de hoje. Por outro lado, traz impactos negativos
Por fim, na seção 4, são feitas as considerações finais.

\section{2_Definições e os principais fatos estilizados}

Um aspecto que vem sendo muito discutido na literatura internacional sobre mercado de trabalho é a dinâmica dos trabalhadores e de postos de trabalho, uma vez que tal análise permite o entendimento do mercado de trabalho tanto em seus aspectos micro como macroeconômicos, permitindo, assim, a compreensão da capacidade de realocação de recursos de dada economia, ou seja, da flexibilidade e da capacidade de reação a choques e mudanças, seja exógenas, seja endógenas.

A flexibilidade no mercado de trabalho é uma característica importante para o bom funcionamento das economias baseadas no mercado, visto que está associada à eficiência alocativa da economia. Davis e Haltiwanger (1992) argumentam que, nas economias ocidentais (EUA, Canadá e Europa Ocidental), cerca de um em cada 10 postos de trabalho são criados e um em cada 10 postos de trabalho são destruídos a cada ano. Esses valores conduzem a uma elevada realocação dos trabalhadores nessas economias; logo, existe elevada rotatividade ${ }^{6}$ de trabalhadores 
entre os postos, fato esse que passa despercebido quando apenas se analisa a questão mediante a análise de mudança líquida do emprego.

Uma vez que vamos analisar os fluxos de trabalho, cabe a definição desses.

\section{1_Definições}

As variáveis de fluxos são definidas conforme o padrão da literatura (Davis; Haltiwanger; Schuh, 1996). Cada taxa é construída a partir da divisão de dado fluxo pela média de emprego de cada firma em dois períodos distintos de tempo. A taxa de criação de empregos (TC) é definida como:

$$
T C_{t}=\frac{L_{t}-L_{t-1}}{0,5\left(L_{t}+L_{t-1}\right)}
$$

se $\mathrm{L}_{\mathrm{t}}>\mathrm{L}_{\mathrm{t}-1}$, ou 0 , se $\mathrm{L}_{\mathrm{t}}<\mathrm{L}_{\mathrm{t}-1}$, em que $\mathrm{L}_{\mathrm{t}}$ é o número de trabalhadores no período t.

Similarmente, a taxa de destruição de empregos é definida como:

$$
T D_{t}=\frac{L_{t-1}-L_{t}}{0,5\left(L_{t}+L_{t-1}\right)}
$$

se $\mathrm{L}_{\mathrm{t}}<\mathrm{L}_{\mathrm{t}-1}$, ou 0 , se $\mathrm{L}_{\mathrm{t}}>\mathrm{L}_{\mathrm{t}-1}$. Adicionalmente, a taxa de variação líquida de empregos $\left(\mathrm{TVL}_{\mathrm{t}}\right.$ ) corresponde à $\mathrm{TC}_{\mathrm{t}}-\mathrm{TD}_{\mathrm{t}}$, e a taxa de realocação de empregos (TR $)$ é igual à $\mathrm{TC}_{\mathrm{t}}+\mathrm{TD}_{\mathrm{t}}$. Finalmente, o excesso de realocação de postos de trabalho (EXC) é a diferença entre a taxa de realocação de empregos e a taxa de variação líquida de empregos, $\mathrm{TR}_{\mathrm{t}}-\mathrm{TVL}_{\mathrm{t}}$.

Uma vez definidos os cinco fluxos a ser utilizados ao longo do artigo, partiremos para a análise dos principais fatos estilizados existentes nessa literatura.

\section{2_Principais fatos estilizados}

Alguns fatos caracterizam a literatura sobre o tema, como a grande realocaçáo existente para que sejam criados empregos, ou o fato de o setor não industrial apresentar taxas de criaçáo de postos de trabalho superiores ao setor industrial, ou ainda o comportamento dos fluxos de criação e destruição de postos de trabalho em relação ao ciclo econômico. As taxas encontradas entre empresas por tamanho e por idade também são alvos de estudos, uma vez que as pequenas e mais novas apresentam taxas de criação e destruição maiores que as empresas de maior porte, o que pode ser derivado dos menores custos trabalhistas e de ajuste enfrentados pelas menores, o que possibilita a essas maior flexibilidade, quando comparadas às maiores empresas.

Davis; Haltiwanger; Schuh (1996, p. 17) nos apresentam as principais características, ou melhor, os fatos estilizados 
sobre o tema. ${ }^{7}$ Eles apontam quatro que consideram principais:

1. Magnitude as taxas de criação e destruição de postos de trabalho são grandes. Ao se considerar o período de um ano, temos que, em média, um em cada 10 postos de trabalho é destruído; contudo, um número comparável de postos é criado em outras atividades;

2. Persistência é verificada alta persistência nas taxas de criação e destruição, tendo em vista que a maior parte dos postos destruídos não reabre na mesma localidade em um intervalo de dois anos;

3. Concentração ocorre concentração das taxas de criação e destruição em firmas que apresentam grandes mudanças no emprego, isto é, cerca de dois terços das taxas de criação e destruição se devem a empresas que expandem ou retraem $25 \%$ ou mais o seu emprego em um intervalo de um ano;

4. Ciclo as taxas de destruição apresentam uma resposta ao ciclo maior que as taxas de criação. As recessóes são caracterizadas por um grande aumento das taxas de destruição e por uma pequena queda na taxa de criação.

Com relação ao fato estilizado da maior ciclicalidade da taxa de destruiçáo, em países em desenvolvimento a taxa de saída do desemprego apresenta alta prociclicalidade, e a taxa de destruição é acíclica, o que pode ser indicação de que a taxa de criação constitui a margem de ajuste ao longo do ciclo em uma parte das economias desenvolvidas (Shimer, 2005a, 2005b).

Um último aspecto que deve ser mencionado é o "industrialismo" existente
${ }^{7}$ Gómez-Salvador e Messina (2003) também avançam na categorização dos principais fatos desta literatura: i) um grande número de postos de trabalho é criado e destruído em todos os países e em todos os setores, independentemente da fase do ciclo econômico; ii) as taxas

\section{de criação e destruição de} empregos são negativamente correlacionadas, mas náo de forma perfeita; iii) a criação de empregos é pró-cíclica, e a destruição. contracíclica; iv) a volatilidade das duas taxas podem diferir entre os diversos países; v) a taxa de realocação é inversamente relacionada com a intensidade de capital das empresas, de forma que mais empregos são criados e destruídos no setor de serviços do que na indústria; vi) a intensidade da realocação depende de várias características das firmas como idade e tamanho, inversamente relacionadas com a taxa de criaçáo de empregos; e por fim vii) a taxa de realocação é um fenômeno persistente, o que faz com que políticas temporárias de emprego surtam pouco efeito, uma vez que existe uma característica estrutural nos fluxos de trabalho. 
na análise dos fluxos de trabalho, ou seja, a focalização de inúmeros trabalhos na análise dos aspectos do emprego industrial. Assim os resultados da literatura podem sofrer um viés para a indústria, sendo uma das preocupaçóes do atual trabalho o esclarecimento dessa questáo. No entanto, conforme Foote (1998), o resultado da ciclicalidade do fluxo de emprego pode estar relacionado ao declínio do setor de manufaturas, fenômeno esse observado em países desenvolvidos, mas ocorre em países em desenvolvimento, em menor escala, em período mais recente.

\section{3 _Metodologia e análise dos resultados}

A metodologia empregada é a da meta-análise, a qual tem sido pouco usada em pesquisas econômicas, principalmente no Brasil. A meta-análise tem sido empregada em diversas áreas do conhecimento e é descrita como uma síntese de pesquisas anteriores sobre um tópico, que apresenta ênfase na produção de conclusóes quantitativas. Ela não constitui uma técnica específica de análise de dados, mas sim uma alternativa analítica que permite reunir resultados e conclusões de outras pesquisas.

O termo "meta-análise" foi empregado, pela primeira vez, no sentido adota- do no presente estudo, por Glass (1976), segundo Finney (1995). A meta-análise se destina a extrair informação adicional de dados preexistentes através da união de resultados de diversos estudos e pela aplicação de uma ou mais técnicas estatísticas. Conforme Luiz (2002), meta-análise é um método quantitativo que permite combinar os resultados, de forma independente, de trabalhos publicados e sintetizar as suas conclusóes ou mesmo obter novas conclusóes. ${ }^{8}$

No presente artigo, foram analisados 62 trabalhos que buscaram calcular as taxas de criação, destruiçáo e realocação de trabalho. Tendo em vista que muitos dos trabalhos apresentam mais de uma estimativa, ou seja, exibem estimativas para vários países, ou para vários anos, ou se valem de várias bases de dados para um mesmo país, foram captadas e analisadas 328 taxas de criação, destruição, realocação, variação líquida e excesso de rotatividade de postos de trabalho.

Os resultados (apresentados na Tabela 1) foram separados da seguinte forma: resultados que apenas analisam a indústria (151 observaçóes) e resultados que avaliam todos os setores (177 observaçóes), resultados por décadas, 1970 (25 observaçóes), 1980 (105 observaçóes), 1990 (135 observaçóes), 2000 (42 observações), por grupos de países separados em

\author{
${ }^{8}$ Pereira (1996) faz uma \\ descrição detalhada de \\ diversas técnicas estatísticas \\ que podem ser usadas na \\ meta-análise. Mais detalhes \\ no uso da meta-análise \\ pode ser encontrados em \\ Wolf (1986), Bailar III (1995), \\ Feinstein (1995), Olkin (1995).
}


Emergentes (80 observações), OCDE (212 observaçóes) e Economias em Transição (36 observaçôes) e, por fim, por origem da legislação trabalhista, ${ }^{9}$ Common Law (119 observaçóes), Civil Law (209 observações), Escandinava (28 observações), Socialista (39 observações), Germânica (11 observaçóes) e Francesa (131 observaçóes).

\subsection{Análise descritiva}

A análise da estatística descritiva indica padróes interessantes no que tange ao grau de desenvolvimento, uma vez que os países em desenvolvimento apresentaram maiores taxas que os desenvolvidos, o que indica que seus mercados são mais agitados que os dos países desenvolvidos. Apesar disso, um dado importante se refere à variação líquida de empregos nos países em desenvolvimento, que é quase sete vezes maior que a apresentada pelos países desenvolvidos.

No que se refere à distinção entre indústria e todos os setores, emergem informaçōes interessantes. A taxa de criação para todos os setores é $16,8 \%$ maior que para a indústria; já a taxa de destruição é 2,6\% menor, ou seja, a indústria cria menos e destrói mais postos de trabalho que a análise por todos os setores. Outro dado que merece destaque refere-se à taxa de variação de postos de trabalho negativa apresentada pela indústria $(-0,60 \%)$, enquanto todos os setores apresentaram taxa positi- va de $(1,32 \%)$. Desta forma, temos que o setor industrial foi um destruidor líquido de empregos durante o período de análise.

Quando partimos para a análise por décadas, percebe-se que todas as taxas (exceto a variação líquida) apresentam-se de forma crescente com o passar das décadas. Ou seja, o mercado de trabalho está se alterando gradualmente, década a década, e se tornando mais flexível. No que tange à taxa de variação líquida, temos que a década de 2000 é a que apresenta a maior criação $(1,04 \%)$, seguida da década de 1970, que apresentou a segunda maior taxa (0,91\%); já a década de $1980(0,23 \%)$ foi a que apresentou a menor taxa. Cabe destacar que todas as décadas apresentaram taxas positivas.

Quando se verificam as taxas por grupos de países (Emergentes, OCDE e Em Transição), percebe-se nítida diferença entre os três. Os Emergentes sáo os que apresentaram maior alteração, com uma taxa média de excesso de rotatividade de $30,76 \%$, bem como elevada taxa de variação líquida (2,70\%). O grupo da $O C D E$ mostrou resultados próximos à média. Já o grupo dos países Em Transiçâo, em razão de todas as transformaçóes vividas por eles, apresentaram variação líquida de $-2,98 \%$, ou seja, grande destruiçáo líquida de postos, apesar de ter mostrado menor "agitação", com taxa de 15,76\%. 
Por fim, no que tange à origem legal da legislação dos países, temos que os países da Common Law exibiram taxas de criação mais baixas, de destruição maiores, e assim variação líquida negativa $(-0,59 \%)$. Dentro do grupo da Civil $L a w$, temos uma criação líquida positiva de $1,02 \%$. Dentro deste grupo, ganha destaque a origem Francesa, que apresentou variação líquida positiva de $2,42 \%$.

$\mathrm{Na}$ análise da diferença de médias, foi realizado um teste t para se observar a significância estatística das diferenças entre as médias. Os resultados encontramse na Tabela 2. Em cada uma das colunas, buscam-se avaliar as diferenças de médias para cada um dos fluxos.

$\mathrm{Na}$ primeira coluna de resultados, são apresentadas as médias e as diferenças entre elas para a taxa de criação de postos de trabalho (TC). Os resultados indicam que, para as décadas de 1970 e 1990, as diferenças não são estatisticamente significantes; já para as décadas de 1980 e 2000, o são, indicando que a primeira apresentou criação estatisticamente inferior às demais décadas, e a segunda, média superior.

Quando avaliada a questáo de setores da economia, percebeu-se que os trabalhos que apenas avaliam a indústria apresentaram taxa de criação menor que os trabalhos que se destinaram a todos os setores, o que nos possibilita argumentar
Tabela 1_Média e desvio-padrão das taxas de criação, destruição e realocação de postos de trabalho com base no levantamento de 62 trabalhos publicados

\begin{tabular}{|c|c|c|c|c|c|}
\hline & TC & TD & TR & TVL & EXC \\
\hline Indústria & $\begin{array}{r}9,9 \\
(3,85) \\
\end{array}$ & $\begin{array}{r}10,51 \\
(3,54) \\
\end{array}$ & $\begin{array}{l}20,41 \\
(6,18) \\
\end{array}$ & $\begin{array}{r}-0,60 \\
(4,08) \\
\end{array}$ & $\begin{array}{l}23,43 \\
(7,13)\end{array}$ \\
\hline Todos os Setores & $\begin{array}{r}11,57 \\
(5,94) \\
\end{array}$ & $\begin{array}{r}10,24 \\
(4,96) \\
\end{array}$ & $\begin{array}{r}21,81 \\
(10,34) \\
\end{array}$ & $\begin{array}{r}1,32 \\
(3,58) \\
\end{array}$ & $\begin{array}{r}24,67 \\
(11,04) \\
\end{array}$ \\
\hline 1970 & $\begin{array}{r}9,73 \\
(1,97) \\
\end{array}$ & $\begin{array}{r}8,82 \\
(2,74) \\
\end{array}$ & $\begin{array}{r}18,56 \\
(2,47)\end{array}$ & $\begin{array}{r}0,91 \\
(4,08) \\
\end{array}$ & $\begin{array}{l}21,66 \\
(4,59) \\
\end{array}$ \\
\hline 1980 & $\begin{array}{l}10,25 \\
(4,04)\end{array}$ & $\begin{array}{l}10,02 \\
(3,38)\end{array}$ & $\begin{array}{l}20,26 \\
(6,28)\end{array}$ & $\begin{array}{r}0,23 \\
(4,00)\end{array}$ & $\begin{array}{l}23,18 \\
(7,29)\end{array}$ \\
\hline 1990 & $\begin{array}{r}10,55 \\
(6,53) \\
\end{array}$ & $\begin{array}{r}10,16 \\
(5,39) \\
\end{array}$ & $\begin{array}{r}20,71 \\
(11,19) \\
\end{array}$ & $\begin{array}{r}0,39 \\
(4,27) \\
\end{array}$ & $\begin{array}{r}23,92 \\
(11,92) \\
\end{array}$ \\
\hline 2000 & $\begin{array}{r}13,58 \\
(3,54) \\
\end{array}$ & $\begin{array}{l}12,54 \\
(3,40) \\
\end{array}$ & $\begin{array}{l}26,12 \\
(6,20) \\
\end{array}$ & $\begin{array}{r}1,04 \\
(3,11) \\
\end{array}$ & $\begin{array}{l}28,64 \\
(6,87) \\
\end{array}$ \\
\hline Emergentes & $\begin{array}{l}14,93 \\
(4,63)\end{array}$ & $\begin{array}{l}12,23 \\
(4,07) \\
\end{array}$ & $\begin{array}{r}27,16 \\
(7,88)\end{array}$ & $\begin{array}{r}2,70 \\
(3,73) \\
\end{array}$ & $\begin{array}{l}30,76 \\
(8,91) \\
\end{array}$ \\
\hline OCDE & $\begin{array}{r}10,31 \\
(4,08) \\
\end{array}$ & $\begin{array}{r}10,15 \\
(4,18)\end{array}$ & $\begin{array}{r}20,46 \\
(7,53)\end{array}$ & $\begin{array}{r}0,16 \\
(3,41) \\
\end{array}$ & $\begin{array}{l}23,00 \\
(8,06)\end{array}$ \\
\hline Transição & $\begin{array}{r}4,50 \\
(4,17) \\
\end{array}$ & $\begin{array}{r}7,46 \\
(4,27) \\
\end{array}$ & $\begin{array}{r}11,96 \\
(7,22) \\
\end{array}$ & $\begin{array}{r}-2,97 \\
(4,37) \\
\end{array}$ & $\begin{array}{l}15,76 \\
(9,11) \\
\end{array}$ \\
\hline Common Law & $\begin{array}{r}10,48 \\
(4,24) \\
\end{array}$ & $\begin{array}{r}11,07 \\
(4,10) \\
\end{array}$ & $\begin{array}{l}21,55 \\
(7,49) \\
\end{array}$ & $\begin{array}{r}-0,59 \\
(3,67) \\
\end{array}$ & $\begin{array}{l}24,40 \\
(8,20)\end{array}$ \\
\hline Civil Law & $\begin{array}{r}10,98 \\
(5,60)\end{array}$ & $\begin{array}{r}9,96 \\
(4,47)\end{array}$ & $\begin{array}{l}20,94 \\
(9,32)\end{array}$ & $\begin{array}{r}1,02 \\
(3,97) \\
\end{array}$ & $\begin{array}{r}23,93 \\
(10,11)\end{array}$ \\
\hline Escandinava & $\begin{array}{r}9,90 \\
(3,00) \\
\end{array}$ & $\begin{array}{r}9,97 \\
(2,90) \\
\end{array}$ & $\begin{array}{r}19,87 \\
(5,25)\end{array}$ & $\begin{array}{l}-0,07 \\
(2,69) \\
\end{array}$ & $\begin{array}{l}21,84 \\
(5,48)\end{array}$ \\
\hline Socialista & $\begin{array}{r}4,94 \\
(4,36) \\
\end{array}$ & $\begin{array}{r}7,68 \\
(4,45) \\
\end{array}$ & $\begin{array}{l}12,63 \\
(7,67) \\
\end{array}$ & $\begin{array}{r}-2,74 \\
(4,34) \\
\end{array}$ & $\begin{array}{l}16,34 \\
(9,21) \\
\end{array}$ \\
\hline Francesa & $\begin{array}{r}13,40 \\
(4,84) \\
\end{array}$ & $\begin{array}{r}10,98 \\
(4,48) \\
\end{array}$ & $\begin{array}{l}24,38 \\
(8,69) \\
\end{array}$ & $\begin{array}{r}2,42 \\
(3,38) \\
\end{array}$ & $\begin{array}{r}27,51 \\
(9,54) \\
\end{array}$ \\
\hline Total & 10,80 & 10,36 & 21,16 & 0,44 & 24,10 \\
\hline
\end{tabular}


que o setor industrial caracterizou-se no período de análise por menor dinamismo na criação de outros postos de trabalho.

Outra preocupação vigente no trabalho foi a identificação entre blocos de países. Neste sentido, foram definidos três grupos de países: $O C D E$, Emergentes e economias Em Transição. As diferenças entre médias dos três grupos foram significativas, o que indica que existem comportamentos distintos entre os grupos de países, sendo identificado que os países da $O C D E$ e Em Transição apresentam taxas de criação abaixo da encontrada pelo grupo de controle a essa variável; os países da $O C D E$ mostraram essa taxa em cerca de $-1,3 \%$ e os países Em Transição em -7\%. Já os países Emergentes apresentaram taxa de criação bem superior ao grupo de controle, indicando que tais economias têm dinâmica de criação de empregos bem superior a dos demais países analisados.

Quando se busca a avaliação da diferença por origem legal da legislação trabalhista, verificou-se que, com relação à taxa de criação, a diferença de médias entre a Civil Law e a Common Law não foram significativas estatisticamente, apesar de o resultado indicar menor dinamismo criador por parte dos países que seguem a Common Law.

Partindo-se para a análise dos subgrupos componentes da Civil Law, a aná- lise nos indica que, com exceção da legislação Escandinava, todas apresentaram médias estatisticamente diferentes, isto é, a legislação Francesa apresentou criação bem superior às demais, ao passo que a Socialista e a Germânica exibiram dinâmicas de criação inferiores.

Quando analisada a diferença da média da economia brasileira ante as demais, percebe-se que o Brasil cria muito mais postos de trabalho que o restante das economias mundiais, ou seja, em média $4 \%$ a mais que as demais economias, o que evidencia um padrão de elevada criação vigente no país.

$\mathrm{Na}$ segunda coluna de resultados $\mathrm{da}$ Tabela 2 são apresentadas as médias e as diferenças entre elas para a taxa de destruição de postos de trabalho (TD). Os resultados indicam que, para as décadas de 1980 e 1990, as diferenças não são estatisticamente significantes; já para as décadas de 1970 e 2000, elas o são, indicando que a primeira apresentou destruição estatisticamente inferior às demais décadas, e a segunda, uma média superior.

Ao se verificar a questáo de setores da economia, percebe-se que os trabalhos que apenas avaliam a indústria apresentaram taxa de destruição maior que os trabalhos que se destinaram a todos os setores; contudo, a diferença entre as médias não foi significativa. 
A diversidade entre médias dos três blocos de países indica que existem comportamentos diferenciados entre os grupos de países. Para aqueles da $O C D E$ e Em Transição, as taxas de destruição ficaram abaixo da encontrada pelo grupo de controle; contudo, apenas os países Em Transição apresentaram resultado significativo estatisticamente. Já os países Emergentes apresentaram taxa de destruição superior ao grupo de controle, o que indica que tais economias têm dinâmica de destruição de empregos superior à dos demais países analisados.

Quando se busca a avaliação da diferença por origem legal da legislação trabalhista, verificou-se que, com relação à taxa de destruição, a diferença de médias entre a Civil Law e a Common Law foi significativa estatisticamente e indica que os países da Common Law destroem mais postos de trabalho do que os da Civil Law.

Se partimos para a análise dos subgrupos componentes da Civil Law, os resultados indicam que, com exceção da legislação Escandinava, todas apresentaram médias estatisticamente diferentes, e a legislação Francesa mostrou destruição superior, enquanto a Socialista e a Germânica exibiram dinâmicas de destruição inferiores.

Se analisada a diferença da média da economia brasileira perante as demais, percebe-se que o Brasil destrói muito mais postos de trabalho que o restante das economias mundiais, isto é, em média $2 \%$ a mais que as demais economias.

$\mathrm{Na}$ terceira coluna de resultados da Tabela 2, são apresentadas as médias e as diferenças entre elas para a taxa de realocação de postos de trabalho (TR). Os resultados indicam que, para a década de 1990, a diferença não é estatisticamente significante; ao contrário das demais décadas, em que isso acontece, indicando que os anos 1970 e 1980 apresentam realocação estatisticamente inferior às demais décadas, e os 2000, média superior.

Quando avaliada a questão de setores da economia, percebe-se que os trabalhos que apenas avaliam a indústria exibiram taxa de realocação menor que os trabalhos que se destinaram a todos os setores; contudo, a diferença entre as médias não foi significativa estatisticamente.

As diferenças entre médias dos três blocos de países foram estatisticamente significativas e apontam que existem comportamentos diferenciados entre os grupos de países, sendo identificado que, nos países da $O C D E$ e Em Transição, a taxa de realocação média situa-se abaixo da encontrada pelo grupo de controle. Os países Emergentes apresentaram taxa de destruição superior ao grupo de controle, o que revela que tais economias têm realocação superior à dos demais países analisados. 
Tabela 2_Diferenças de médias entre os grupos de tratamento e controle para as taxas de criação, destruição e realocação de postos de trabalho com base no levantamento de 62 trabalhos publicados

\begin{tabular}{|c|c|c|c|c|c|c|c|c|c|c|c|c|c|c|c|}
\hline & (A) & (B) & (A)-(B) & (A) & (B) & (A)-(B) & (A) & (B) & $(A)-(B)$ & (A) & (B) & $(A)-(B)$ & (A) & (B) & $(A)-(B)$ \\
\hline \multirow{3}{*}{$\begin{array}{l}\stackrel{2}{\Omega} \\
\Omega\end{array}$} & 9.732 & 88 & -1.156 & 8.824 & 10.489 & -1.665 & 8.556 & 21.377 & -2.821 & 0.908 & 0.398 & -0.509 & 21.656 & 24.300 & -2.644 \\
\hline & $(0.393)$ & $(0.305)$ & $(1.070)$ & $(0.547)$ & $(0.255)$ & $(0.904)$ & $(0.494)$ & $(0.516)$ & $(1.804)$ & $(0.815)$ & $(0.225)$ & $(0.819)$ & (0.918) & $(0.558)$ & (1.963) \\
\hline & $\mathrm{N}=25$ & $\mathrm{~N}=303$ & $\mathrm{t}=-1.1$ & $\mathrm{~N}=25$ & $\mathrm{~N}=303$ & $\mathrm{t}=-1.8^{* *}$ & $\mathrm{~N}=25$ & $\mathrm{~N}=303$ & $\mathrm{t}=-1.5^{*}$ & $\mathrm{~N}=25$ & $\mathrm{~N}=303$ & $\mathrm{t}=-0.6$ & $\mathrm{~N}=25$ & $\mathrm{~N}=303$ & $\mathrm{t}=-1.3^{*}$ \\
\hline \multirow{3}{*}{$\begin{array}{l}\curvearrowright \\
\curvearrowright \\
\curvearrowright\end{array}$} & 10.246 & 11.060 & -0.814 & 10.017 & 10.525 & -0.508 & 20.263 & 21.586 & -1.322 & 0.228 & 0.535 & 0.306 & 23.177 & 24.533 & -1.355 \\
\hline & $(0.393)$ & $(0.373)$ & $(0.608)$ & $(0.329)$ & $(0.318)$ & $(0.516)$ & $(0.612)$ & $(0.643)$ & $(1.027)$ & $(0.389)$ & $(0.261)$ & $(0.466)$ & $(0.7113)$ & $(0.689)$ & (1.117) \\
\hline & $\mathrm{N}=105$ & $\mathrm{~N}=223$ & $\mathrm{t}=-1.3^{*}$ & $N=105$ & $\mathrm{~N}=223$ & $\mathrm{t}=-0.9$ & $\mathrm{~N}=105$ & $N=223$ & $\mathrm{t}=-1.2^{*}$ & $\mathrm{~N}=105$ & $\mathrm{~N}=223$ & $\mathrm{t}=0.6$ & $\mathrm{~N}=105$ & $N=223$ & $\mathrm{t}=-1.2$ \\
\hline \multirow{3}{*}{ ล } & 10.550 & 10.974 & -0.424 & 10.159 & 10.504 & -0.345 & 20.709 & 21.479 & -0.769 & 0.390 & 0.469 & 0.078 & 23.920 & 24.223 & -0.303 \\
\hline & $(0.562)$ & $(0.281)$ & $(0.577)$ & $(0.464)$ & $(0.250)$ & $(0.490)$ & $(0.963)$ & $(0.461)$ & $(0.9754)$ & $(0.367)$ & $(0.265)$ & $(0.442)$ & $(1.025)$ & $(0.523)$ & (1.061) \\
\hline & $\mathrm{N}=135$ & $\mathrm{~N}=193$ & $\mathrm{t}=-0.7$ & $N=135$ & $\mathrm{~N}=193$ & $\mathrm{t}=-0.7$ & $\mathrm{~N}=135$ & $\mathrm{~N}=193$ & $\mathrm{t}=-0.7$ & $\mathrm{~N}=135$ & $\mathrm{~N}=193$ & $\mathrm{t}=0.11$ & $N=135$ & $\mathrm{~N}=193$ & $\mathrm{t}=-0.2$ \\
\hline \multirow{3}{*}{$\begin{array}{l}\stackrel{\bigcirc}{\circ} \\
\bigcirc\end{array}$} & 13.579 & 10.391 & 3.188 & 12.535 & 10.043 & 2.492 & 26.115 & 20.435 & 5.680 & 1.044 & 0.348 & -5.680 & 28.640 & 23.432 & 5.208 \\
\hline & $(0.545)$ & $(0.308)$ & $(0.833)$ & $(0.523)$ & $(0.260)$ & $(0.708)$ & $(0.956)$ & $(0.519)$ & $(1.403)$ & $(0.479)$ & $(0.238)$ & $(1.403)$ & $(1.060)$ & $(0.567)$ & (1.5371) \\
\hline & $N=42$ & $\mathrm{~N}=286$ & $\mathrm{t}=3.8^{* * *}$ & $\mathrm{~N}=42$ & $\mathrm{~N}=286$ & $\mathrm{t}=3.5^{* * *}$ & $\mathrm{~N}=42$ & $\mathrm{~N}=286$ & $\mathrm{t}=4.0^{* * *}$ & $\mathrm{~N}=42$ & $\mathrm{~N}=286$ & $\mathrm{t}=-1.0$ & $N=42$ & $\mathrm{~N}=286$ & $\mathrm{t}=3.3^{* * *}$ \\
\hline \multirow{3}{*}{ 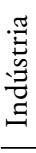 } & 9.902 & 11.565 & $-1,662$ & 10.505 & 10.241 & 0.2644 & 20.408 & 21.806 & -1.397 & -0.602 & 1.324 & -1.926 & 23.430 & 24.669 & -1.238 \\
\hline & $(0.312)$ & $(0.446)$ & $(0.563)$ & $(0.289)$ & $(0.372)$ & $(0.484)$ & $(0.502)$ & $(0.777)$ & $(0.961)$ & $(0.332)$ & $(0.269)$ & $(0.423)$ & $(0.5794)$ & $(0.830)$ & $(1.046)$ \\
\hline & $N=151$ & $\mathrm{~N}=177$ & $\mathrm{t}=-3^{* * *}$ & $N=151$ & $\mathrm{~N}=177$ & $\mathrm{t}=0.5$ & $N=151$ & $\mathrm{~N}=177$ & $\mathrm{t}=-1.4^{*}$ & $N=151$ & $\mathrm{~N}=177$ & $\mathrm{t}=-4^{* * *}$ & $N=151$ & $\mathrm{~N}=177$ & $\mathrm{t}=-1.1$ \\
\hline \multirow{3}{*}{$\stackrel{1}{\varrho}$} & 10.311 & 11.691 & $-1,379$ & 10.152 & 10.747 & -0.595 & 20.464 & 22.439 & -1.97526 & 0.159 & 0.944 & -0.784 & 23.001 & 26.105 & -3.104 \\
\hline & $(0.280)$ & $(0.612)$ & $(0.590)$ & $(0.287)$ & $(0.434)$ & $(0.503)$ & $(0.516)$ & $(0.966)$ & (0.999) & $(0.234)$ & $(0.438)$ & $(0.452)$ & $(0.553)$ & (1.051) & (1.079) \\
\hline & $\mathrm{N}=212$ & $\mathrm{~N}=116$ & $\mathrm{t}=-2^{* *}$ & $\mathrm{~N}=212$ & $N=116$ & $\mathrm{t}=-1.1$ & $\mathrm{~N}=212$ & $N=116$ & $\mathrm{t}=-1.9^{* *}$ & $\mathrm{~N}=212$ & $N=116$ & $\mathrm{t}=-1.7^{* *}$ & $\mathrm{~N}=212$ & $\mathrm{~N}=116$ & $\mathrm{t}=-3^{* * *}$ \\
\hline \multirow{3}{*}{ 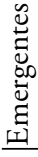 } & 14.929 & 9.467 & 5.462 & 12.226 & 9.761 & 2.464 & 27.156 & 19.229 & 7.926 & 2.703 & -0.293 & 2.997 & 30.762 & 21.949 & 8.812 \\
\hline & $(0.5175)$ & $(0.290)$ & $(0.589)$ & $(0.455)$ & $(0.272)$ & $(0.545)$ & $(0.881)$ & $(0.511)$ & $(1.029)$ & $(0.416)$ & $(0.236)$ & $(0.478)$ & $(0.995)$ & $(0.545)$ & (1.114) \\
\hline & $\mathrm{N}=80$ & $\mathrm{~N}=248$ & $\mathrm{t}=9.2^{* * *}$ & $\mathrm{~N}=80$ & $\mathrm{~N}=248$ & $\mathrm{t}=4.5^{* * *}$ & $\mathrm{~N}=80$ & $\mathrm{~N}=248$ & $\mathrm{t}=7.6^{* * *}$ & $\mathrm{~N}=80$ & $\mathrm{~N}=248$ & $\mathrm{t}=6.2^{* * *}$ & $\mathrm{~N}=80$ & $\mathrm{~N}=248$ & $\mathrm{t}=7.9^{* * *}$ \\
\hline \multirow{3}{*}{ 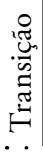 } & 4.496 & 577 & 7080 & 7.461 & 10.720 & -3.258 & 11 & 22.297 & -10.339 & -2.965 & 0.856 & -3.821 & 15.758 & 25.127 & -9.368 \\
\hline & $(0.694)$ & $(0.275)$ & $(0.821)$ & $(0.712)$ & $(0.248)$ & $(0.750)$ & $(1.204)$ & $(0.478)$ & $(1.427)$ & $(0.728)$ & $(0.214)$ & $(0.663)$ & (1.517) & $(0.525)$ & (1.589) \\
\hline & $N=36$ & $\mathrm{~N}=292$ & $\mathrm{t}=-8^{* * *}$ & $\mathrm{~N}=36$ & $\mathrm{~N}=292$ & $\mathrm{t}=-4^{* * *}$ & $\mathrm{~N}=36$ & $\mathrm{~N}=292$ & $t=-7$ & $\mathrm{~N}=36$ & $\mathrm{~N}=292$ & $t=-5^{* * *}$ & $\mathrm{~N}=36$ & $\mathrm{~N}=292$ & $t=-6$ \\
\hline
\end{tabular}

Nota: (1) Entre parênteses o erro padrão; (A) Grupo de Tratamento, (B) Grupo de Controle.

Legenda: p-valor $0.01\left(^{(* *)}\right) ; 0.05\left(^{* *}\right) ; 0.10\left(^{*}\right)$ 
Tabela 2_Diferenças de médias entre os grupos de tratamento e controle para as taxas de criação, destruição e realocação de postos de trabalho com base no levantamento de 62 trabalhos publicados

\begin{tabular}{|c|c|c|c|c|c|c|c|c|c|c|c|c|c|c|c|}
\hline & & $\begin{array}{l}\text { TC } \\
\text { (B) }\end{array}$ & & (A) & $\begin{array}{l}\text { TD } \\
\text { (B) }\end{array}$ & & & (B) & & & in & & & $\begin{array}{l}\text { EXC } \\
\text { (B) }\end{array}$ & (B) \\
\hline בే & $\begin{array}{l}10.482 \\
(0.388) \\
\mathrm{N}=119\end{array}$ & $\begin{array}{r}10.980 \\
(0.3873) \\
N=209\end{array}$ & $\begin{array}{l}-0.498 \\
(0.591) \\
t=-0.8\end{array}$ & $\begin{array}{l}11.069 \\
(0.376) \\
N=119\end{array}$ & $\begin{array}{c}9.960 \\
(0.308) \\
N=209\end{array}$ & $\begin{array}{c}1.109 \\
(0.498) \\
\mathrm{t}=2.2^{* * *} \\
\end{array}$ & $\begin{array}{c}21.551 \\
(0.686) \\
N=119\end{array}$ & $\begin{array}{l}20.941 \\
(0.644) \\
N=209\end{array}$ & $\begin{array}{r}0.610 \\
(0.999) \\
\mathrm{t}=0.6\end{array}$ & $\begin{array}{l}-0.586 \\
(0.336) \\
N=119\end{array}$ & $\begin{array}{r}1.020 \\
(0.274) \\
N=209\end{array}$ & $\begin{array}{l}-1.607 \\
(0.443) \\
\mathrm{t}=-3^{* * *}\end{array}$ & $\begin{array}{l}24.403 \\
(0.7519) \\
N=119\end{array}$ & $\begin{array}{l}23.925 \\
(0.699) \\
N=209\end{array}$ & $\begin{array}{c}0.477 \\
(1.086) \\
t=0.4\end{array}$ \\
\hline 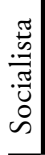 & $\begin{array}{r}4.944 \\
(0.698) \\
N=39\end{array}$ & $\begin{array}{l}11.590 \\
(0.277) \\
\mathrm{N}=289\end{array}$ & $\begin{array}{l}-0.045 \\
(0.798) \\
\mathrm{t}=-8^{* * *}\end{array}$ & $\begin{array}{r}7.683 \\
(0.712) \\
N=39\end{array}$ & $\begin{array}{l}10.724 \\
(0.248) \\
N=289\end{array}$ & $\begin{array}{l}(0.726) \\
t=-4^{* * *}\end{array}$ & $\begin{array}{c}12.028 \\
(1.227) \\
N=39\end{array}$ & $\begin{array}{l}(0.480) \\
\mathrm{N}=289\end{array}$ & $\begin{array}{l}-9.686 \\
(1.385) \\
t=-7^{* * *}\end{array}$ & $\begin{array}{r}(0.695) \\
N=39\end{array}$ & $\begin{array}{l}(0.216) \\
N=289\end{array}$ & $\begin{array}{l}-3.604 \\
(0.641) \\
t=-5^{* * *}\end{array}$ & $\begin{array}{l}(1.475) \\
N=39\end{array}$ & $\begin{array}{l}25.145 \\
(0.529) \\
\mathrm{N}=289\end{array}$ & $\begin{array}{l}(1.539) \\
\mathrm{t}=-5^{* * *}\end{array}$ \\
\hline 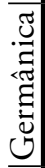 & $\begin{array}{r}6.277 \\
(0.648) \\
\mathrm{N}=11 \\
\end{array}$ & $\begin{array}{l}10.956 \\
(0.289) \\
\mathrm{N}=317\end{array}$ & $\begin{array}{l}-4.679 \\
(1.559) \\
\mathrm{t}=-3^{* * *}\end{array}$ & $\begin{array}{r}5.873 \\
(0.586) \\
N=11 \\
\end{array}$ & $\begin{array}{l}10.518 \\
(0.243) \\
\mathrm{N}=317\end{array}$ & $\begin{array}{l}-4.644 \\
(1.315) \\
\mathrm{t}=-3^{* * *}\end{array}$ & $\begin{array}{r}12.150 \\
(1.093) \\
\mathrm{N}=11\end{array}$ & $\begin{array}{l}21.475 \\
(0.485) \\
\mathrm{N}=317 \\
\end{array}$ & $\begin{array}{l}-9.324 \\
(2.619) \\
t=-3^{* * *}\end{array}$ & $\begin{array}{r}0.403 \\
(0.578) \\
\mathrm{N}=11 \\
\end{array}$ & $\begin{array}{c}0.438 \\
(0.223) \\
N=317\end{array}$ & $\begin{array}{l}-0.034 \\
(1.208) \\
t=-0.0\end{array}$ & $\begin{array}{r}13.474 \\
(1.063) \\
\mathrm{N}=11 \\
\end{array}$ & $\begin{array}{l}24.467 \\
(0.526) \\
\mathrm{N}=317\end{array}$ & $\begin{array}{l}-10.993 \\
(2.838) \\
\mathrm{t}=-4^{* * *}\end{array}$ \\
\hline 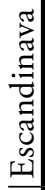 & $\begin{array}{l}(0.567) \\
N=28\end{array}$ & $\begin{array}{l}10.883 \\
(0.305) \\
N=300\end{array}$ & $\begin{array}{l}-0.983 \\
(1.016) \\
t=-0.9\end{array}$ & $\begin{array}{r}9.971 \\
(0.547) \\
N=28\end{array}$ & $\begin{array}{l}10.399 \\
(0.258) \\
\mathrm{N}=300\end{array}$ & $\begin{array}{l}-0.427 \\
(0.863) \\
t=-0.4\end{array}$ & $\begin{array}{c}19.871 \\
(0.992) \\
N=28\end{array}$ & $\begin{array}{l}21.283 \\
(0.516) \\
\mathrm{N}=300\end{array}$ & $\begin{array}{l}-1.411 \\
(1.718) \\
\mathrm{t}=-0.8\end{array}$ & $\begin{array}{c}-0.071 \\
(0.508) \\
N=28\end{array}$ & $\begin{array}{r}0.484 \\
(0.232) \\
N=300\end{array}$ & $\begin{array}{l}-0.556 \\
(0.778) \\
\mathrm{t}=-0.7\end{array}$ & $\begin{array}{l}21.835 \\
(1.036) \\
\mathrm{N}=28\end{array}$ & $\begin{array}{l}24.310 \\
(0.561) \\
\mathrm{N}=300\end{array}$ & $\begin{array}{l}-2.474 \\
(1.865) \\
t=-2^{* * *}\end{array}$ \\
\hline 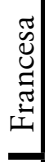 & $\begin{array}{l}13.403 \\
(0.422) \\
\mathrm{N}=131 \\
\end{array}$ & $\begin{array}{r}9.068 \\
(0.327) \\
\mathrm{N}=197\end{array}$ & $\begin{array}{r}4.335 \\
(0.529)\end{array}$ & $\begin{array}{l}10.979 \\
(0.391) \\
\mathrm{N}=131\end{array}$ & $\begin{array}{r}9.952 \\
(0.302) \\
N=197 \\
\end{array}$ & $\begin{array}{c}1.026 \\
(0.489) \\
t=2.1^{* *}\end{array}$ & $\begin{array}{l}24.382 \\
(0.759) \\
N=131 \\
\end{array}$ & $\begin{array}{l}19.021 \\
(0.571)\end{array}$ & $\begin{array}{c}5.361 \\
(0.935)\end{array}$ & $\begin{array}{c}2.424 \\
(0.294) \\
N=131\end{array}$ & $\begin{array}{l}-0.884 \\
(0.265) \\
N=197\end{array}$ & $\begin{array}{c}3.308 \\
(0.404) \\
t=8.1^{* * *}\end{array}$ & $\begin{array}{l}27.507 \\
(0.833) \\
N=131\end{array}$ & $\begin{array}{l}21.832 \\
(0.619) \\
N=197\end{array}$ & $\begin{array}{r}5.675 \\
(1.019) \\
t=5.5^{* * *}\end{array}$ \\
\hline$\overline{3}$ & $\begin{array}{l}14.384 \\
(0.600)\end{array}$ & $\begin{array}{l}(0.3016) \\
\mathrm{N}=286\end{array}$ & $\begin{array}{l}(0.820) \\
t=5.0^{* * *}\end{array}$ & $\begin{array}{l}(0.515) \\
N=42\end{array}$ & $\begin{array}{l}(0.262) \\
N=286\end{array}$ & $\begin{array}{l}(0.714) \\
t=2.7^{* * *}\end{array}$ & $\begin{array}{r}(0.990) \\
N=42\end{array}$ & $\begin{array}{l}(0.515) \\
N=286\end{array}$ & $\begin{array}{l}(1.398) \\
\mathrm{t}=4.3^{* * *}\end{array}$ & $\begin{array}{l}(0.521) \\
N=42\end{array}$ & $\begin{array}{l}(0.233) \\
N=286\end{array}$ & $\begin{array}{l}(0.640) \\
t=3.3^{* * *}\end{array}$ & $\begin{array}{l}(1.069) \\
\mathrm{N}=42\end{array}$ & $\begin{array}{l}(0.561) \\
N=286\end{array}$ & (1.522) \\
\hline
\end{tabular}

Nota: (1) Entre parênteses o erro padrăo; (A) Grupo de Tratamento, (B) Grupo de Controle.

Legenda: p-valor $0.01\left(^{* * *}\right) ; 0.05\left(^{* *}\right) ; 0.10\left(^{*}\right)$ 
No momento em que se busca a avaliação da diferença por origem legal da legislação trabalhista, verifica-se que, com relação à taxa de realocação, a diferença de médias entre a Civil Law e a Common Law não foi significativa estatisticamente.

De acordo com a análise dos subgrupos componentes da Civil Law, os resultados indicam que, com exceção da legislação Escandinava, todas apresentaram médias estatisticamente diferentes, e a legislação Francesa, realocação superior, ao passo que a Socialista e a Germânica mostraram dinâmicas de realocação inferiores.

Quando analisada a diferença da média da economia brasileira perante as demais, percebe-se que o Brasil realoca muito mais postos de trabalho que o restante das economias mundiais, em média $6 \%$ a mais que as demais economias, fato já esperado, uma vez que tanto a destruição como a criaçáo foram maiores que a média dos demais países.

$\mathrm{Na}$ quarta coluna de resultados da Tabela 2, veem-se as médias e as diferenças entre elas para a taxa de realocação de variação líquida de postos de trabalho (TVL). Os resultados indicam que não há diferença significativa entre as décadas nesse quesito.

Quando avaliada a questão de setores da economia, percebeu-se que os trabalhos que apenas avaliam a indús- tria apresentaram taxa de variação líquida bem menor que os que se destinaram a todos os setores, cerca de $2 \%$ menor, o que é bastante significativo, indicando que o setor é um destruidor líquido de postos de trabalho, cabendo aos demais, em particular o setor serviços, dinâmica mais positiva na criação líquida de postos de trabalho.

As diferenças entre médias dos três blocos de países foram estatisticamente significativas e indicam que existem comportamentos diferenciados entre os grupos de países, sendo identificado que nos países da $O C D E$ e nos Em Transição, a taxa de criação líquida foi negativa, ou seja, ocorreu destruição líquida nos dois conjuntos de países, com destaque para a magnitude da destruição líquida para aqueles Em Transição. Os Emergentes, por sua vez, mostraram taxa de criação líquida positiva e bastante expressiva, o que corrobora com a análise de que esses países possuem forte dinâmica de criação de postos de trabalho.

Ao se avaliar a diferença por origem legal da legislação trabalhista, verificou-se que, com relação à taxa de criação líquida, a diferença de médias entre a $C i$ vil Law e Common Law foram significativas estatisticamente, indicando que os países da Common Law apresentam destruição líquida de postos de trabalho, e 
os países da Civil Law mostraram taxa de criação líquida positiva.

Partindo-se para a análise dos subgrupos componentes da Civil Law, os resultados indicam que a legislação Escandinava e a Germânica não são estatisticamente significativas na diferença de médias. A legislação Francesa apresentou criação líquida superior, enquanto a Socialista exibiu dinâmica de destruição líquida de postos de trabalho.

Quando analisada a diferença da média da economia brasileira ante as demais, percebe-se que o Brasil cria liquidamente muito mais postos de trabalho que o restante das economias analisadas.

Na última coluna da Tabela 2, são apresentadas as médias e as diferenças entre elas para a taxa de excesso de realocação de postos de trabalho (EXC). Os resultados indicam que as diferenças para as décadas de 1990 e 1980 não são significativas estatisticamente; já a década de 1970 apresenta resultado significativo estatisticamente, o que indica um mercado de trabalho "mais calmo" nessa década. Para a década de 2000, o resultado aponta maior agitação, com taxas de excesso de rotatividade superiores às das demais décadas.

Ao se avaliar a questão de setores da economia, o resultado foi estatisticamente não significativo, apesar de apon- tar que o setor industrial apresenta agitação inferior a todos os setores.

As diferenças entre as médias dos três blocos de países foram estatisticamente significativas e apontam que existem comportamentos diferenciados entre os grupos de países, sendo identificado que os da $O C D E$ e os Em Transição apresentam mercados de trabalho mais estáveis que os países Emergentes, onde a agitação foi superior.

Com relação à avaliação da diferença por origem legal da legislação trabalhista, verificou-se que a diferença de médias entre a Civil Law e a Common Law não foi significativa estatisticamente.

Ao se analisar os subgrupos componentes da Civil Law, os resultados indicam que todas as diferenças entre médias são estatisticamente significativas. A legislação Francesa apresenta agitação no mercado de trabalho, com maior movimentação entre os trabalhadores. Já as legislações Socialista, Escandinava e Germânica mostraram médias inferiores para o excesso de rotatividade de postos de trabalho.

Quando analisada a diferença da média da economia brasileira diante das demais, percebe-se que este país tem um mercado de trabalho bastante agitado, com média bem superior à apresentada pelas outras economias analisadas. 


\subsection{Análise econométrica}

A fim de comprovar as evidências encontradas na análise das estatísticas descritivas, foi estimado um modelo econométrico buscando a mensuração das relaçóes existentes e a sua comparação com os resultados dos fatos estilizados e das estatísticas descritivas apresentadas neste trabalho. Além disso, foram inseridas duas variáveis macroeconômicas, isto é, a taxa de crescimento do PIB e a taxa de abertura da economia, no intuito de testar a influência de fatores de demanda agregada e de movimento cíclico (PIB), e aspectos atrelados ao setor externo (abertura, aqui definida como o somatório do percentual de exportaçóes e de importações em função do PIB).

O modelo especificado a ser estimado é dado por:

Os resultados esperados são os seguintes:

Fluxos $(J C, J D, G J R, N E G, E X C)=\beta_{0}+$

$+\beta_{1} 1970+\beta_{2} 1980+\beta_{3} 1990+\beta_{4} 2000+$

$+\beta_{5}$ indoestria $+\beta_{6}$ T.setores $+\beta_{7} O C D E+$

$+\beta_{8}$ Emergentes $+\beta_{9}$ Transição $+\beta_{10}$ CommonLaw +

$+\beta_{11}$ CivilLaw $+\beta_{12}$ TxCrescimento $+\beta_{13}$ Abertura $+\varepsilon$

(i) Décadas: são esperados coeficientes crescentes, ou seja, $\beta_{1}<\beta_{2}<\beta_{3}<$ $\beta_{4}$, uma vez que foi verificado que os fluxos crescem ao longo das décadas;

(ii) Setores: esperam-se resultados de $\beta_{6}>\beta_{5}$ para todos os fluxos, com exceção do TD;

(iii) Blocos de países: resultados esperados de $\beta_{8}>\beta_{7}>\beta_{9}$, ou seja, os Emergentes apresentando o mercado de trabalho mais movimentado em todos os fluxos;

(iv) Legislação: Common Law exibindo coeficientes maiores que os mostrados pela Civil Law $\left(\beta_{10}>\beta_{11}\right)$;

(v) Crescimento econômico: de acordo com a literatura, espera-se pouco impacto no TC e impactos maiores na TD e na TVL;

(vi) Abertura: países com maior abertura devem apresentar maior movimentação no mercado de trabalho.

Os resultados encontrados podem ser vistos na Tabela 3. Para maior clareza na exposição, vamos analisá-los por blocos de variáveis (Décadas, Setores, Blocos de Países, Legislação, Crescimento e Abertura).

$\mathrm{Na}$ avaliação do comportamento dos Fluxos ao longo das décadas, perce- 
be-se que as de 1980 e 1990 não apresentaram significância estatística para nenhum dos fluxos. A única década em que se pode observar coeficientes significativos para todos os fluxos foi a de 2000. A década de 1970 exibiu resultados significativos para a TD, a TR e a TVL.

Quanto aos valores dos parâmetros ao longo das décadas, os resultados apontaram que ocorre tendência crescente para todos os fluxos (exceto a variação líquida), indicando que os mercados se tornaram mais flexíveis com o passar do tempo, ou seja, as economias passaram a criar e a destruir mais postos de trabalho; contudo, essa maior "flexibilidade" não conduziu a maior criação líquida de postos de trabalho, ou melhor, os mercados se tornaram mais "agitados", e a "dança das cadeiras" do emprego sofreu mudança estrutural, uma vez que a "música" ficou mais rápida, mas a quantidade de cadeiras diminuiu, fazendo com que trabalhadores se movimentem mais, e cada vez menos cadeiras novas são colocadas.

Quando pensamos em termos do aumento populacional existente ao longo das décadas, esses resultados apontam indícios interessantes para a análise do desemprego, que cada vez mais se torna estrutural. Os indícios aqui mostram uma triste realidade: cada vez mais, as po- pulações aumentam, e a criação líquida se torna menor, quando não negativa.

Com relação aos setores, temos que os coeficientes de criação e criação líquida para a indústria foram significativos e negativos, indicando relação negativa entre a criação bruta ou a líquida dos estudos que levaram em consideração a indústria apenas. $\mathrm{O}$ coeficiente para a destruição foi positivo e significativo, o que corrobora com a interpretação de que o setor industrial vem destruindo e criando cada vez menos postos de trabalho.

Já para os estudos que levam em consideração todos os setores, os coeficientes indicam dinâmica positiva de criação de trabalho, seja em termos líquidos, seja em termos brutos. O coeficiente para a taxa de destruição não foi significativo. Outro aspecto que vale a pena ser discutido é que os trabalhos para todos os setores apresentam coeficientes bastante significativos para a realocação e o excesso de realocaçáo, indicando relação de maior volatilidade nos mercados de trabalho, quando se estudam todos os setores, com especial ênfase o setor serviços, o qual apresenta dinâmica de contratação e demissão mais volátil que o setor industrial.

Quando analisamos por blocos de países, temos que os países da $O C D E$ apenas apresentam coeficiente significativo 
Tabela 3 - Resultados dos modelos econométricos estimados

\begin{tabular}{|c|c|c|c|c|c|}
\hline Variável/Fluxo & $\begin{array}{l}\mathrm{JC} \\
\mathrm{R} 2=0.3661 \\
\mathrm{~F}=17.84 \% \\
\mathrm{~N}=320\end{array}$ & $\begin{array}{l}\mathrm{JD} \\
\mathrm{R} 2=0.2529 \\
\mathrm{~N}=320\end{array}$ & $\begin{array}{l}\text { GJR } \\
F=12.70 \% \\
N=320\end{array}$ & $\begin{array}{l}\text { NEG }=0.4469 \\
F=24.97 \% \\
N=320\end{array}$ & $\begin{array}{l}\text { EXC } \\
F 2=0.2552 \\
\mathrm{~N}=10.59 \\
\end{array}$ \\
\hline 1970 & $\begin{array}{r}-0.0430194 \\
(0.7229833)\end{array}$ & $\begin{array}{r}-1.880345 \\
(0.664883)^{* * *}\end{array}$ & $\begin{array}{c}-2.182914 \\
(1.285298)^{*}\end{array}$ & $\begin{array}{c}2.096875 \\
(0.52698)^{* * *}\end{array}$ & $\begin{array}{l}-1.933348 \\
(1.432145)\end{array}$ \\
\hline 1980 & $\begin{array}{r}-0.1947451 \\
(0.4210263) \\
\end{array}$ & $\begin{array}{r}-0.1230541 \\
(0.3871922) \\
\end{array}$ & $\begin{array}{r}-0.5526837 \\
(0.7484881) \\
\end{array}$ & $\begin{array}{r}0.1631936 \\
(0.3068853) \\
\end{array}$ & $\begin{array}{r}-0.4077622 \\
(0.8340037) \\
\end{array}$ \\
\hline 1990 & $\begin{array}{r}-0.1509883 \\
(0.4634575) \\
\end{array}$ & $\begin{array}{r}0.6210487 \\
(0.4262135) \\
\end{array}$ & $\begin{array}{l}0.2252194 \\
(0.823921) \\
\end{array}$ & $\begin{array}{r}-0.5271961 \\
(0.3378133) \\
\end{array}$ & $\begin{array}{l}0.2616356 \\
0.9180549 \\
\end{array}$ \\
\hline 2000 & $\begin{array}{r}1.388753 \\
(0.5664043)^{* *} \\
\end{array}$ & $\begin{array}{r}2.382351 \\
(0.520887)^{* * *} \\
\end{array}$ & $\begin{array}{r}3.510378 \\
(1.0069)^{* * *} \\
\end{array}$ & $\begin{array}{r}-0.7328723 \\
(0.41285)^{*} \\
\end{array}$ & $\begin{array}{r}3.079475 \\
(1.1219)^{* * *} \\
\end{array}$ \\
\hline Indústria & $\begin{array}{c}-0.6702939 \\
(0.29407)^{* *} \\
\end{array}$ & $\begin{array}{c}0.6024431 \\
(0.27043)^{* *} \\
\end{array}$ & $\begin{array}{r}-0.5749653 \\
(0.5227912) \\
\end{array}$ & $\begin{array}{c}-0.7656223 \\
(0.2143)^{* * *} \\
\end{array}$ & $\begin{array}{r}-0.3787586 \\
(0.5825207) \\
\end{array}$ \\
\hline Todos & $\begin{array}{r}1.670294 \\
(0.29407)^{* * *} \\
\end{array}$ & $\begin{array}{r}0.3975569 \\
(0.2704394) \\
\end{array}$ & $\begin{array}{r}1.574965 \\
(0.5227)^{* * *} \\
\end{array}$ & $\begin{array}{r}1.765622 \\
(0.21434)^{* * *} \\
\end{array}$ & $\begin{array}{c}1.378759 \\
(0.58252)^{* *} \\
\end{array}$ \\
\hline OCDE & $\begin{array}{r}0.7032025 \\
(0.4386487) \\
\end{array}$ & $\begin{array}{r}0.0740565 \\
(0.4033984) \\
\end{array}$ & $\begin{array}{r}0.4370844 \\
(0.7798166) \\
\end{array}$ & $\begin{array}{c}0.9693207 \\
(0.31973)^{* * *} \\
\end{array}$ & $\begin{array}{r}-0.7275284 \\
(0.8689116) \\
\end{array}$ \\
\hline Emer & $\begin{array}{r}5.295159 \\
(0.52638)^{* * *} \\
\end{array}$ & $\begin{array}{r}1.882214 \\
(0.48408)^{* * *} \\
\end{array}$ & $\begin{array}{r}6.853904 \\
(0.9357)^{* * *} \\
\end{array}$ & $\begin{array}{r}3.736414 \\
(0.38368)^{* * *} \\
\end{array}$ & $\begin{array}{c}7.421229 \\
(1.0427)^{* * *} \\
\end{array}$ \\
\hline Transição & $\begin{array}{r}-4.998362 \\
(0.629536)^{* * *} \\
\end{array}$ & $\begin{array}{c}-0.9562705 \\
(0.5789461)^{*} \\
\end{array}$ & $\begin{array}{c}-6.290988 \\
(1.1191)^{* * *} \\
\end{array}$ & $\begin{array}{c}-3.705735 \\
(0.45886)^{* * *} \\
\end{array}$ & $\begin{array}{c}-5.693701 \\
(1.2470)^{* * *} \\
\end{array}$ \\
\hline Common Law & $\begin{array}{r}1.146052 \\
(0.3305585)^{* * *} \\
\end{array}$ & $\begin{array}{c}1.434929 \\
(0.3039)^{* * *} \\
\end{array}$ & $\begin{array}{r}2.083109 \\
(0.5876)^{* * *} \\
\end{array}$ & $\begin{array}{r}0.208994 \\
(0.2409435) \\
\end{array}$ & $\begin{array}{c}2.414323 \\
(0.65479)^{* * *} \\
\end{array}$ \\
\hline Civil Law & $\begin{array}{r}-0.1460516 \\
(0.3305585) \\
\end{array}$ & $\begin{array}{r}-0.4349294 \\
(0.3039945) \\
\end{array}$ & $\begin{array}{c}-1.083109 \\
(0.587657)^{*} \\
\end{array}$ & $\begin{array}{r}0.791006 \\
(0.24094)^{* * *} \\
\end{array}$ & $\begin{array}{c}-1.414323 \\
(0.65479)^{* * *} \\
\end{array}$ \\
\hline $\begin{array}{l}\text { Taxa de Crescimento } \\
\text { do PIB }\end{array}$ & $\begin{array}{r}0.1075227 \\
(0.0812331) \\
\end{array}$ & $\begin{array}{r}-0.357511 \\
(0.07470)^{* * *} \\
\end{array}$ & $\begin{array}{c}-0.2500794 \\
(0.144413)^{*} \\
\end{array}$ & $\begin{array}{r}0.4651249 \\
(0.05921)^{* * *} \\
\end{array}$ & $\begin{array}{l}-0.3296006 \\
(0.160913)^{* *} \\
\end{array}$ \\
\hline Abertura & $\begin{array}{r}0.000799 \\
(0.0081843)\end{array}$ & $\begin{array}{c}-0.0280763 \\
(0.007526)^{* * *}\end{array}$ & $\begin{array}{r}-0.027006 \\
(0.01454)^{*}\end{array}$ & $\begin{array}{l}0.0286039 \\
(0.0059)^{* * *}\end{array}$ & $\begin{array}{l}-0.0218906 \\
(0.0162122)\end{array}$ \\
\hline
\end{tabular}

Nota: (1) Entre parênteses o erro padráo; (2) Todas as regressóes incluem um intercepto, cujos resultados náo são reportados na tabela acima. Legenda: p-valor $0.01\left(^{(* *}\right) ; 0.05\left({ }^{* *}\right) ; 0.10\left(^{*}\right)$ 
para a criação líquida. O coeficiente encontrado é positivo e em valor intermediário entre o encontrado para os Emergentes (mais alto de todos) e dos países Em Transição (menor e negativo). Desta análise, podemos concluir que os Emergentes são os que apresentam a maior dinâmica de criaçãoo líquida. Esse fato é considerado quando se observa o elevado coeficiente para a criação bruta apresentado por esse conjunto de países. Os Emergentes também mostram o maior coeficiente para a destruição bruta de postos de trabalho; contudo, em valor bem inferior ao apresentado pela criação bruta, o que faz com que esses países apresentem a já citada elevada criação líquida.

Os países Emergentes também são os que exibem as maiores taxas de realocação e excesso de realocação, fato esse derivado das substantivas taxas de criação e destruição de postos de trabalho. O que podemos concluir é que tais economias são as mais dinâmicas na criação, mas para isso efetuam elevada rotatividade entre os trabalhadores.

Já os países Em Transição apresentam uma dinâmica marcada pelo momento de profundas mudanças econômicas, que são refletidas nos negativos coeficientes de criação bruta e líquida.

Quando analisamos a questão da legislação, os resultados indicam que, apesar de os coeficientes para criação e destruição não serem significativos para a Civil Law (valores negativos), a Common Law apresentou coeficientes positivos para as duas, o que vai ao encontro com a hipótese de que a legislação pautada na Common Law estimula a criaçáo e a destruição de postos de trabalho. No que tange à criação líquida, o coeficiente para a Common Law não foi significativo, mas o da Civil Law o foi, indicando aumento da criaçâo líquida para países com legislação pautada na Civil Law. No que tange à realocação e ao excesso de realocação, os coeficientes para as duas origens de legislação foram significativos, e os resultados indicam que os países da Common Law apresentam ganho tanto na realocação como no excesso, caracterizando, assim, mercados de trabalho mais flexíveis.

No que tange à variável de crescimento, os resultados indicaram que, conforme os fatos estilizados, a taxa de destruição é mais sensível que a taxa de criação (que não foi significativa). Os sinais dos coeficientes indicam que o crescimento tem relação negativa com a destruição de postos de trabalho, bem como com a taxa de realocaçáo e com o excesso de rotatividade. Com relação à taxa de criação líquida, temos que existe relação direta. Desta forma, quanto maior a taxa de crescimento, menor a destruição de postos de 
trabalho, menor a realocação e o excesso de rotatividade, e maior a criação líquida. Desta forma, a melhor dinâmica de criação líquida de postos de trabalho apresentada pelos países Emergentes tem relação forte com o maior crescimento econômico apresentado por essas economias.

Para se ter uma ideia mais precisa dos impactos do crescimento econômico sobre os fluxos, foram calculadas as elasticidades. Os resultados encontrados foram os seguintes: TC $(0,024)$, TD $(-0,085)$, TR $(-0,029)$, TVL $(2,611)$ e EXC $(-0,033)$. Esses apontam para uma forte realidade, isto é, $1 \%$ a mais de crescimento conduz a uma criação líquida 2,6\% maior, ou seja, existe forte relação entre a variação líquida e a taxa de crescimento da economia.

Por fim, a relação existente entre a abertura da economia e os fluxos, em que destacamos a relação negativa existente entre a abertura e a destruição de postos de trabalho, bem como a relaçáo positiva existente no que concerne à variação líquida e à abertura da economia.

A análise das elasticidades aponta para os seguintes resultados: TC $(0,0036)$, TD $(-0,15)$, TR $(-0,071)$, TVL $(3,54)$ e EXC $(-0,048)$. Conforme destacado por Menezes et al. (2002), a elasticidade da criação líquida de empregos é elevada, o que mostra que, quanto mais abertas as economias, mais empregos são gerados.

\section{Conclusões}

Este artigo realizou uma meta-análise sobre os fluxos de emprego no intuito de testar as evidências para os fatos estilizados dessa literatura e também verificar outros fatos e relação existentes na literatura sobre os fluxos de trabalho.

Os principais resultados encontrados apontam em direção da confirmação de alguns fatos estilizados, como o de que o setor industrial destrói mais empregos e cria menos empregos do que a economia como um todo, o que pode servir para reforçar a ideia de desindustrialização (Rowthorn; Ramaswamy, 1999), ou seja, de que cada vez mais, o emprego vem se deslocando do setor industrial para o setor serviços. No entanto, essa conclusão só seria possível se pudéssemos utilizar microdados conectáveis empregado-empregador, ${ }^{10}$ já que o aumento de emprego no setor serviços simultaneamente à diminuição do emprego na indústria não quer dizer, necessariamente, que os trabalhadores da indústria foram para o setor de serviços.

Nosso trabalho soma à literatura internacional ao promover uma sistematização e comparação desses fatos para uma gama ampla de países, o que possibilita contemplar vários níveis de desenvolvimento. As evidências reforçaram o fato estilizado de que, nos países desenvolvidos, a mudança estrutural rumo a
${ }^{10}$ Como em Abowd;

Kramarz; Margolis (1999). 
uma maior participação do setor serviços antecede a que ocorre nos países em desenvolvimento, uma vez que esses países, por apresentarem renda per capita menor, não estariam substituindo a indústria por um setor de serviços mais avançado, sendo prejudicial tal tendência.

Com base na verificação da distinta dinâmica de fluxos de trabalho entre a indústria e a economia como um todo, observou-se a ocorrência de uma mudança no perfil de composição do PIB nos países em estudo. A composição média foi de $5,15 \%$ para a agricultura, $32,28 \%$ para a indústria e $62,59 \%$ para os serviços.

Quando se parte para a análise da evolução da composição por década, percebe-se que ocorre aumento da participação dos serviços, de 59,84\% em 1970 para $68,20 \%$ em 2000, e redução na participação da indústria, de 34,64\% para 28,56\%. Assim, percebemos a tendência de que a composição setorial do PIB tem influência nos fluxos de emprego, uma vez que o padrão dos fluxos (crescente) encontrado para décadas indica aumento desses.

O aumento dos fluxos ao longo das décadas nos leva a induzir que os mercados se tornaram mais flexíveis com o passar dessas décadas, o que pode estar associado a maior abertura econômica que as economias se expuseram a partir da década de 1980 e 1990, com o advento das po- líticas neoliberais e da globalização. Além disso, o próprio Consenso de Washington traz consigo uma série de recomendações associadas a maior flexibilidade no mercado de trabalho, recomendaçóes essas seguidas por diversas economias, inclusive pela brasileira.

Um fato que merece ser destacado é o de que as décadas de 1980 e 1990 apresentam as menores taxas de variação líquida. Esse fato pode estar associado ao ajuste que muitas economias passaram ao longo dessas décadas, como o fenômeno de histerese do desemprego na Europa, na década de 1980, de hiperinflação e de descontrole macroeconômico nas economias latino-americanas e transição econômica no Leste Europeu.

As menores taxas apresentadas pela década de 1970 podem estar associadas aos choques do petróleo, que provocaram ajustamento produtivo às economias por todo o mundo, fazendo com que o ritmo de crescimento da economia mundial sofresse desaceleração.

Outro grupo de controle realizado no trabalho foi por origem legal da legislação trabalhista dos países, e a discussão mais detalhada pode ser encontrada em Botero et al. (2004). A análise de diferenças entre as legislaçóes foi realizada em dois estágios. No primeiro, consideramos a origem dos dois grandes gru- 
pos de legislação trabalhista, a Civil Law e a Common Law. Botero et al. (2004) argumentam que países ricos regulam menos o seu mercado de trabalho do que os países mais pobres. Alegam também que países da Civil Law possuem níveis mais altos de legislação trabalhista, e que esses níveis mais elevados estão associados a uma maior eclosão de economia informal, menor participaçáo da força de trabalho e desemprego mais elevado (especialmente entre os jovens).

Os resultados indicaram que os países da Civil Law têm taxas de criação e de variaçáo líquida superiores, ou seja, nesses países temos uma criação de trabalho maior, o que vai ao (de encontro = ao contrário) encontro dessa origem legal, que é mais restritiva à movimentação dos trabalhadores.

Já os países da Commom Law apresentaram taxa de destruição superior às dos países da Civil Law, o que fez com que tais países apresentassem taxa de destruição líquida de postos de trabalho. Além disso, os países da Common Law mostraram realocação e excesso de rotatividade superiores aos da Civil Law, se bem que as margens foram pequenas.

Outra análise possível pauta-se no detalhamento das diferentes formas da Civil Law, a saber: Escandinava, Socialista, Germânica e Francesa. Merece desta- que a Legislação Francesa, por apresentar as maiores taxas de criaçáo bruta e líquida de postos de trabalho, bem como maior realocaçáo e excesso de rotatividade. Essa origem legal, de acordo com Botero et al. (2004), é uma das que mais regulam o mercado de trabalho. Desta forma, a análise por origem legal da legislação trabalhista nos indica que os países que mais regulam, e logo, deveriam apresentar menor movimentação no mercado de trabalho, são os que mais criam empregos, de forma líquida e bruta, e também os que apresentam mercados de trabalho mais agitados. Somando esse fato à verificação de que a composição média do setor de serviços nos países Emergentes é inferior ao dos países da $O C D E$, e que é neste setor que se tem maior movimentação no mercado de trabalho, e que, pelo fato de se ter maior ocupaçáo neste setor, a tendência é que tais países em desenvolvimento continuem a apresentar taxas mais elevadas de criação, mesmo com a legislação trabalhista menos propícia para tal.

Para melhor compreensão de como os fluxos se comportam entre os diferentes países, foram realizados dois controles por blocos de países. No primeiro, foi analisada a questão por blocos econômicos, assim distribuídos: Emergentes, Em Transição e $O C D E$. Os resultados encon- 
trados são interessantes, uma vez que os países Emergentes apresentaram taxas superiores em todos os fluxos. Merecem especial atenção as taxas de criação e variação líquida que são substancialmente maiores que a dos países da $O C D E$ e dos países em Transição. Isso indica que essas economias estáo criando mais vagas e mais oportunidades de emprego que os países da $O C D E$ e países Em Transição, embora apresentem legislação trabalhista mais rígida.

Vale destacar que os resultados encontrados para os países Em Transição são bem ruins, o que reflete o momento econômico-histórico turbulento que esses países passavam, sendo as taxas calculadas aqui pautadas em estudos desse momento, logo, enviesadas para ele.

Quanto ao grau de desenvolvimento das economias, analisamos por dois grupos: Desenvolvidos e Em Desenvolvimento. Os resultados indicam que os países Em Desenvolvimento apresentam criação de empregos maior que os Desenvolvidos, além de apresentarem criação líquida cerca de sete vezes maior, o que indica mercados de trabalho mais agitados e com maiores possibilidades de contratação, apesar de serem os países mais pobres os que apresentam, de forma contraditória, legislação mais rígida. Adicionalmente ao fato de os países Em Desenvolvimento terem passado por processos de liberalização, fatores institucionais no mesmo grupo de países indicam ainda a falta de flexibilidade no mercado de trabalho, o que também afeta o grau de realocação e a produtividade, conforme enfatizam Rogerson e Restuccia (2007).

No que se refere à análise por crescimento econômico e por grau de abertura, as relações encontradas são bem diretas: quanto maior o crescimento e quanto maior a abertura da economia, maior será a criação líquida de empregos, uma vez que a destruição se torna menor.

Por fim, os dados revelam que o Brasil apresenta dinâmica bem diferenciada no que tange aos fluxos de emprego, possuindo criação, destruiçấo e realocação bem acima da média mundial, o que demonstra que, apesar da forte regulação trabalhista existente em nossa economia, a dinâmica de criação é robusta. 


\section{Referências bibliográficas}

\author{
ABOWD, J. M.; KRAMARZ, \\ F; MARGOLIS, D. N. High \\ wages workers and high wage \\ firms. Econometrica, n. 67, \\ p. 251-333, 1999.
}

BAILAR III, J. C. The practice of meta-analysis. Journal of Clinical Epidemiology, v. 48, n. 1, p. 149-157, 1995.

BOTERO, J.; DJANKOV, S.; LA PORTA, R.; LOPEZ-DESILANES, F.; SHLEIFER,

A. The regulation of labor.

Quarterly Journal of Economics, November, 2004.

DAVIS, S. J.; HALTIWANGER, J. Gross job creation, gross job destruction and employment reallocation. Quarterly Journal of Economics, n. 106, p. 819-63, 1992.

DAVIS, S. J.; HALTIWANGER, J. Gross job flows. In: ASHENFELTER, O.; CARD, D. (Eds.). Handbook of labor economics. Amsterdam: Elsevier, 3b, 1999.

DAVIS, S. J.; HALTIWANGER, J.; SCHUH, S. Job creation and job destruction. Cambridge, MA: MIT Press, 1996.
FEINSTEIN, A. R. Metaanalysis: Statistical alchemy for the 21st century. Journal of Clinical Epidemiology, v. 48, n. 1, p. 71-79, 1995.

FINNEY, D. A statistician at meta-analysis. Journal of Clinical Epidemiology, v. 48, n. 1, p. 87-103, 1995.

FOOTE, C. Trend employment growth and the bunching of job creation and destruction. Quarterly Journal of Economics, v. 113, n. 3, p. 809-834, 1998.

GLASS, G. V. Primary, secondary and meta-analysis of research. Educational Research, v. 5, p. 3-8, 1976.

Gómez-Salvador, R.; MESSINA, J. Gross job flows and institutions in European countries. IZA Working Paper, 2003.

LUIZ, A. J. B. Meta-análise: Definição, aplicaçôes e sinergia com dados espaciais. Cadernos de Ciência \& Tecnologia, v. 19, n. 3 , p. 407-428, 2002.

OLKIN, I. Statistical and theoretical considerations in meta-analysis. Journal of Clinical Epidemiology, v. 48, n. 1, p. 133-146, 1995.
PEREIRA, M. C. A. Elementos de meta-análise. Dissertação Departamento de Estatística, Universidade de Brasília, Brasília. 1996.

ROGERSON, R.; RESTUCCIA, D. Policy distortions and aggregate productivity with heterogeneous plants. NBER Working Paper wp13018, 2007

ROWTHORN. R.; RAMASWAMY, R. Growth, trade, and deindustrialization. International Monetary Fund (IMF) Staff Papers, vol. 46, 1999.

SHIMER, R. The cyclical behavior of equilibrium unemployment and vacancies. American Economic Review, vol. 95, n. 1, p. 25-49, 2005 a.

SHIMER. R. Reassessing the ins and outs of unemployment. University of Chicago (mimeo), 2005b.

WOLF, F. M. Meta-analysis: Quantitative methods for research synthesis. Newbury Park, CA: Sage, 65p. (Series, 07-059), 1986. 


\section{Referências auxiliares (origem dos dados)}

ABOWD, J.; CORBEL, P.; KRAMARZ, F. The entry and exit of workers and the growth of employment: An analysis of French establishments. Review of Economic and Statistics, v. 81, n. 2, p. 170-187, 1999.

ACQUISTI, A.; Lehmann, $\mathrm{H}$. Job creation and job destruction in the Russian Federation.

Trinity Economic Paper Series Paper No. 2000/1, 2000.

Acs, Z.; Amington, C.; Robb, A. Measures of job flow dynamics in the U.S. economy. CRIEFF Discussion Papers 9907, Centre for Research into Industry, Enterprise, Finance and the Firm, 1999.

Allaart, P.; Kerkhofs, M.; VoogdHamelink, M. Simultaneous job creation and job destruction on establishment level. OSA WP2000-7, 2000.

ALBAEK, K.; SØRENSEN, B. Worker flows and job flows in Danish manufacturing, 19801991. Economic Journal, 108, p. 1.750-1.771, 1998.

ANDERSON, P.; MEYER, B. The extent and consequences of job turnover. Brookings Papers: Microeconomics, n. 6, p. 177-248, 1994.
BALDWIN, J. R.; GORECKI.

P. K. Firm entry and exit in the Canadian manufacturing sector, 1970-1982. Canadian Journal of Economics, May 1991, p. 300-323.

\section{BALDWIN, J.; DUNNE,}

\section{T.; HALTIWANGER, J. A} comparison of job creation and job destruction in Canada and the United States. The Review of Economics and Statistics, v. 80, n. 3, p. 347-356, 1998.

BARNES, M.; HASKEL, J. Job creation, job destruction and small firms: Evidence for the UK. Queen Mary, University of London, 2001.

BAUER, T.; BENDER,

$S$. Technological change, organizational change, and job turnover. IZA Discussion Paper No. $570,2002$.

BLANCHARD, O.; PORTUGAL, P. What hides behind an unemployment rate: Comparing Portuguese and US labor markets. American Economic Review, n. 91, p. 187-207, 2001.
BLANCHFLOWER, D.; BURGESS, S. Job creation and job destruction in Great Britain in the 1980s. Industrial and Labor Relations Review, n. 50, p. 17-38, 1996.

BÖCKERMAN, P.; MALIRANTA, M. Regional disparities in gross job and worker flows in Finland. Finnish Economic Papers, Vol. 14,

No 2, 2001.

BOERI, T.; CRAMER, U.

Employment growth, incumbents and entrants: Evidence from Germany. International Journal of Industrial Organization, n. 10, p. 545-565, 1992

Bojnec, S.; Jozef, Konings. Job creation, job destruction and labour demand in Slovenia. LICOS Discussion Papers 7498, LICOS - Centre for Institutions and Economic Performance, 1998.

Broersma L.; Gautier P. A. Job flows in Dutch manufacturing, 1979-1993. Empirical Evidence and Theoretical Implications. De Economist, Vol. 145, № 1, 1997.

CAMHI, A.; ENGLE, E.; MICCO, A. Dinâmica de empleo y productividad em manufacturas: Evidencia micro e consecuencias macro. In:
MORNDE, F.; VERGARA, R. (Eds.). Analísis empirica del crescimiento en Chile. Santiago: Centro de Estudos Publicos, jun. 1997.

CENTENO, M.; MACHADO, C.; NOVO, A. A criação e destruição de emprego em Portugal. Boletim Econômico, Banco de Portugal, 2007.

CONTINI, B.; REVELLI, R. Gross flow vs. net flows in the labor market: What is there to be learned? Labour Economics, n. 4, p. 245-263, 1997.

CORSEUIL, C. H.; SERVO, L. Criação, destruição, realocação de empregos no Brasil. Brasília: Ipea, 2006.

CORSEUIL, C. H. et al.

Criação, destruição, realocação de emprego no Brasil. Rio de Janeiro: Ipea, 2002 (Texto para Discussão, n. 855).

DAVIS, S. J.; HALTIWANGER, J. Gross job creation and destruction: microeconomic evidence and macroeconomic implications. In: BLANCHARD, O.; FISCHER, S. (Eds.). NBER Macroeconomics Annual 1990. Cambridge: University Press, 1991. 
DAVIS, S. J.; HALTIWANGER,

J. Gross job creation, gross job destruction and employment reallocation. Quarterly Journal of Economics, n. 106, p. 81963, 1992

DAVIS, S. J.; HALTIWANGER, J. Gross job flows. In: ASHENFELTER, O.; CARD D. (Eds.). Handbook of labor economis, Amsterdan: Elsevier, 3b, 1999.

DAVIS, S. J.; HALTIWANGER, J.; SCHUH, S. Job creation and Job destruction. Cambridge, MA: MIT Press, 1996.

DAVIS, S. J.; HALTIWANGER, J.; FABERMAN, R. The flow approach to labor markets: New data sources and micro-macro links. NBER Working Paper 12167, 2006

Duhautois, R. Les réallocations d'emplois en France sont-elles en phase avec le cycle? Économie et Statistique, n 351, 2002.

DUNNE, T.; ROBERTS, M.; SAMULESON, L. Plant turnover and gross employment flows in the US manufacturing sector. Journal of Labor Economics, n. 7, p. 48-71, 1989.

FAGGIO, G. Does trade libearlization induce job reallocation and productivity growth? Evidence on countries of Central and Eastern Europe. Department of Economics K.U. Leuven, 2000.
FAGGIO, G.; KONINGS, J. Job creation, job destruction and employment growth in transition countries in the 90's. IZA

Discussion Paper No. 242, 2001.

GALLAGHER, C. C.; DALY, M. C.; THOMASON, J. C.

The growth of U.K. companies 1 985-87 and their contribution to job generation. Small Business Economics, Vol. 3, p. 269-286, 1991.

GARIBALDI, P. Job flows and plant size dynamics: Traditional measures and alternative econometric techniques. Labour, CEIS, Fondaziona Giacomo Brodocini and Blackwell Publishing Ltd., v. 4, n. 2, p. 185-212, 2000.

GENDA, Y. Job gains and losses in Japan: A comparison with Italy. Japan Labor Bulletin, v. 37, n. 1, 1998. Disponível em: <http://www.jil.go.jp/bulletin/ year/1998/vol37 01/05.htm>. Acesso em: 20 de janeiro de 2009.

Gómez-Salvador, R.; MESSINA, J. Gross job flows and institutions in European countries. IZA Working Paper, 2003.

GOOS, M. Labour demand, firm growth and the evolution of industries. IZA Working Paper, 2000.

\section{GOURINCHAS, P.-O.}

Exchange rates do matter: French job reallocation and exchange rate turbulence, 1984-1992.

European Economic Review, n. 43, p. 1.279-1.316, 1999.
GREY, A. Job gains and job losses: Recent literature and trends. OECD Jobs Study Working Papers, No 1, 1995.

HAMDANI, D. Job creation, job destruction and job reallocation in the Canadian economy. Science and Technology Redesign Project, Statistics Canada, 1998.

Hijzen, A.; Upward, R.; Wright, P. Job creation, job destruction and the role of small firms: Firm-level evidence for the UK. Research paper series, Globalisation and Labour Markets, 2007.

Homsy, G.; Costa, M. Criação e destruiçấo de empregos na indústria brasileira: Uma análise. IPEA, Brasília, 2006.

Kaplan, D.; González, G.; Robertson, R. Worker- and job-flows in Mexico, 2005.

KLETTE, T. J.; MATHIASSEN, A. Job creation, job destruction and plant turnover in Norvegian manufacturing. Annales d'Économie et de Statistique, 41/42, p. 97-125, 1996.

KONINGS, J.; LEHMANN, H.; SCHAFER, M. Job creation and job destruction in a transition economy: Ownership, firm size, and gross job flows in Polish manufacturing 1988-91, CERT, 1996

Lawless, M.; Murphy,

A. Job turnover in Irish manufacturing,1972-2006. Central Bank of Ireland, 2008.
LEONARD, J. In the wrong place at the wrong time: The extent of frictional and structural unemployment. In: LAND, K.; LEONARD, J. (Eds.). Unemployment structure of labor markets. New York: Brasil Blackwell, 1987.

MADUREIRA, H. Criação e destruiçấo de postos de trabalho no setor formal brasileiro: Uma abordagem por gênero. 2004. Dissertação (Mestrado em Economia) - Faculdade de Ciências Econômicas, Universidade Federal de Minas Gerais, Belo Horizonte, 2004.

MUMFORD, K.; SMITH, P. N. Job reallocation and average job tenure: Theory and workplace evidence from Australia. Department of Economics, University of York, 1999.

OECD, Employment Outlook, Paris, September, 1987.

PAZELLO, E.; BIVAR, W.; GONZAGA, G. Criação e destruição de postos de trabalho por tamanho da empresa na indústria brasileira. Pesquisa e Planejamento Econômico, Rio de Janeiro, v. 30, p. 259-288, 2001.

PICOT, G.; BALDWIN, J.; DUPUY, G. Have small firms created a disproportionate share of new jobs in Canada? A reassessment of the facts, Canadian Economics Association Meetings, No. 71, 1994. 


\section{PICOT, G.; DUPUY, G Job}

creation by company size class:

Concentration and persistence of job gains and losses in Canadian Companies. Bussiness and Labour Market Analysis Division. Canada 1996 (Research Paper, n. 93).

REUBEN Gronau \& Haim Regev, 1997. "The Demand for Labor and Job Turnover: Israeli Manufacturing 1970 - 1994," Working Papers 757, Princeton University, Department of Economics, Industrial Relations Section.

Reinecke, G.; Ferrada, C. Creación y destrucción de empleo en Chile: Análisis de datos longitudinales de la ACHS, 2005.

RIBEIRO, E. P. Fluxos de empregos, fluxos de trabalhadores e fluxos de postos de trabalhos no Brasil. Cidade, Editora, 2007.

ROBERTS, M. J. Employment flows and producer turnover. In: ROBERTS, M. E.; TYBOUT,

J. (Eds.). Industry evolution in developing countries: Micro patterns of turnover productivity and market structure. New York: Oxford Univ. Press, 1996.

\section{ROWTHORN. R.;}

RAMASWAMY, R.

(1999). Growth, trade, and

deindustrialization. International Monetary Fund (IMF) Staff

Papers, Vol. 46.

\section{SALVANES, K. G. Market} rigidities and labour marker flexibility: An international comparison. Scandinavian Journal of Economics, Vol. 99, p. 315-333, 1997.

SPLETZER. The contribution of establishment births and deaths to employment growth. Journal of Business and Economics Statistics, n. 18, p. 113-126, 1998

STILGLBAURER, A. et al. Job creation and job destruction in a regulated labor market: The case of Austria. Oesterreichische National Bank (Austrian Central Bank), 2002 (Working Paper, n. 78).

TSOU M.-W. et al. Worker turnover and job reallocation in Taiwanese manufacturing. Applied Economics, n. 34, p. 410-411, 2002.

Tsou, M.; Liu, J; Hammitt, J. Worker flows and job flows in Taiwan. Economics Letters 73, 2001.

Voulgaris, F.; Papadogonas, T.; Agiomirgianakis, G. Job creation and job destruction in Greek manufacturing. Review of Development Economics, Vol. 9, N. 2, p. 289-301, 2005.

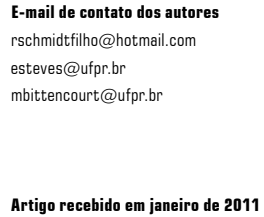


Anexo A Trabalhos analisados, origem dos dados.

(continua)

\begin{tabular}{|c|c|c|c|c|c|}
\hline País & Autores & $\begin{array}{l}\text { Período } \\
\text { de análise }\end{array}$ & País & Autores & $\begin{array}{l}\text { Período } \\
\text { de análise }\end{array}$ \\
\hline Alemanha & Bauer e Bender (2004) & $1995-1996$ & Alemanha & Contini e Revelli (1997) & $1977-1990$ \\
\hline Alemanha & Boeri e Cramer (1992) & $1977-1989$ & Alemanha & Faggio e Konings (2001) & $1988-1995$ \\
\hline Alemanha & Gomez-Salvador e Messina (2003) & $1994-2000$ & Alemanha & Grey (1995) & $1983-1990$ \\
\hline ARGENTINA & Haltiwanger et al. (2004) & $1991-2001$ & AUSTRÁLIA & Mumford e Smith (1999) & $1988-1989$ \\
\hline Aústria & Gomez-salvador e Messina (2003) & $1995-2000$ & Aústria & Stiglbaurer et al. (2002) & $1978-1998$ \\
\hline Bélgica & Goos (2000) & $1986-1995$ & Bélgica & Faggio e Konings (2001) & $1989-1995$ \\
\hline Bélgica & Gomez-Salvador e Messina (2003) & $1992-2000$ & Brasil & Homsy e Costa (2006) & $1997-2002$ \\
\hline Brasil & CORSEUIL et al. (2006) & $1992-2000$ & Brasil & CORSEUIL et al. (2002) & $1997-1998$ \\
\hline Brasil & Madureira (2004) & $1985-2001$ & Brasil & Ribeiro (2007) & 1996-2001 \\
\hline Brasil & Haltiwanger et al. (2004) & $1992-2000$ & Brasil & Pazello et al. (2000) & 1986-1995 \\
\hline Bulgária & Faggio e Konigs (2001) & 1994-1997 & Canadá & Baldwin et al. (1998) & $1974-1992$ \\
\hline Canadá & Baldwin e Gorecki (1998) & $1970-1981$ & Canadá & OCDE (1987) & $1979-1984$ \\
\hline Canadá & OCDE (1994) & $1983-1991$ & Canadá & Hamdani (1998) & 1984-1994 \\
\hline Canadá & Picot et al. (1994) & $1978-1992$ & Chile & Reinecke e Ferrada (2005) & $1997-2003$ \\
\hline Chile & Camhi, Engle e Micco (1997) & $1981-1992$ & Chile & Haltiwanger et al. (2004) & 1980-1999 \\
\hline Chile & Roberts (1996) & $1979-1986$ & Colômbia & Haltiwanger et al. (2004) & 1978-1999 \\
\hline Colômbia & Roberts (1996) & $1977-1991$ & Dinamarca & Albaek e Sorensen (1998) & $1980-1990$ \\
\hline Dinamarca & Gomez-salvador e Messina (2003) & $1996-2001$ & Dinamarca & Grey (1995) & 1980-1988 \\
\hline Eslovênia & Faggio e Konigs (2001) & $1994-1997$ & Eslovênia & Bojnec e Honings (1998) & $1991-1996$ \\
\hline Espanha & Gomez-salvador e Messina (2003) & $1994-2000$ & Estônia & Faggio e Konigs (2001) & 1994-1997 \\
\hline Estônia & Haltiwanger e Vodopivec (2001) & $1989-1994$ & Estados Unidos & Baldwin et al. (1998) & $1973-1993$ \\
\hline Estados Unidos & Davis e Haltiwanger (1992) & $1973-1986$ & Estados Unidos & Acs, Armington e Robb (1999) & $1990-1995$ \\
\hline Estados Unidos & Anderson e Meyer (1994) & 1979-1984 & Estados Unidos & Anderson e Meyer (1994) & $1979-1984$ \\
\hline Estados Unidos & Davis e Haltiwanger (1991) & $1972-1986$ & Estados Unidos & Davis et al. (2006) & $1998-2002$ \\
\hline Estados Unidos & $\begin{array}{r}\text { Davis, Haltiwanger e Schuh } \\
\text { (1996) } \\
\end{array}$ & $1973-1988$ & Estados Unidos & DunnE et al. (1989) & $1963-1982$ \\
\hline Estados Unidos & Grey (1995) & $1976-1990$ & Estados Unidos & Haltiwanger e Schuh (1999) & $1972-1993$ \\
\hline Estados Unidos & Leonard (1987) & $1978-1982$ & Estados Unidos & Haltiwanger e Schuh (1999) & $1972-1993$ \\
\hline
\end{tabular}




\begin{tabular}{|c|c|c|c|c|c|}
\hline País & Autores & $\begin{array}{l}\text { Período } \\
\text { de análise }\end{array}$ & País & Autores & $\begin{array}{l}\text { (conclusão) } \\
\text { Período } \\
\text { de análise }\end{array}$ \\
\hline Finlândia & Bockerman e Maliranta (2001) & $1990-1997$ & Finlândia & Gomez-salvador e Messina (2003) & $1997-2000$ \\
\hline Finlândia & Grey (1995) & $1986-1991$ & França & Abowd et al. (1999) & $1987-1990$ \\
\hline França & Gomez-salvador e Messina (2003) & $1993-2000$ & França & Gourinchas (1999) & $1984-1992$ \\
\hline França & Grey (1995) & $1978-1992$ & Grécia & Voulgaris et al. (2005) & 1995-1999 \\
\hline Holanda & Allaart et al. (2000) & 1997 & Holanda & Broersma e Gautier (1997) & $1978-1993$ \\
\hline Holanda & Faggio e Konigs (2001) & $1988-1995$ & Holanda & Gomez-salvador e Messina (2003) & $1994-2000$ \\
\hline Irlanda & Lawless e Murphy (2008) & $1972-2007$ & Irlanda & Gomez-salvador e Messina (2003) & $1994-2000$ \\
\hline Israel & Gronau \& Regev (1997) & $1987-1989$ & Itália & Contini e Reveli (1997) & $1984-1993$ \\
\hline Itália & Contini e Reveli (1997) & $1984-1994$ & Itália & Contini e Reveli (1997) & 1984-1989 \\
\hline Itália & Grey (1995) & 1985-1991 & Japão & Genda (1998) & $1991-1995$ \\
\hline Marrocos & Roberts (1996) & 1984-1989 & México & Kaplan et al. (2005) & $1986-2001$ \\
\hline México & Garibaldi (2000) & $1985-1990$ & México & Haltiwanger et al. (2004) & $1994-2000$ \\
\hline Noruega & Klette e Mathiassen (1996) & $1977-1986$ & Noruega & Salvanes (1997) & $1977-1992$ \\
\hline Nova Zelândia & Grey (1995) & $1987-1992$ & Polônia & Faggio e Konigs (2001) & 1994-1997 \\
\hline Polônia & $\begin{array}{r}\text { Konings, Lehmann e Schafer } \\
\text { (1996) }\end{array}$ & $1988-1991$ & Portugal & Centeno, Machado e Novo (QP) (2007) & $1996-2005$ \\
\hline Portugal & $\begin{array}{r}\text { Centeno, Machado e Novo } \\
\text { (BDRSS) (2007) }\end{array}$ & $2001-2006$ & Portugal & Blanchard e Portugal (2001) & $1983-1995$ \\
\hline Portugal & Gomez-salvador e Messina (2003) & $1995-2000$ & Reino Unido & Blanchflower e Burgess (1996) & $\begin{array}{r}1980,1984 \\
1990 \\
\end{array}$ \\
\hline Reino Unido & Hijzen, Upward e Wright (2007) & $1998-2005$ & Reino Unido & Barnes e Haskel (2002) & $1981-1991$ \\
\hline Reino Unido & Hijzen, Upward e Wright (2007) & $1998-2005$ & Reino Unido & Faggio e Konigs (2001) & $1987-1995$ \\
\hline Reino Unido & Gallagher et al. (1990) & $1985-1987$ & Reino Unido & Gomez-salvador e Messina (2003) & $1992-2000$ \\
\hline Reino Unido & Grey (1995) & $1982-1991$ & Romênia & Faggio e Konigs (2001) & $1995-1997$ \\
\hline Rússia & Acquisti e Lehman (2000) & 1997 & Suécia & Gomez-salvador e Messina (2003) & $1998-2001$ \\
\hline Suécia & Grey (1995) & $1985-1991$ & Suécia & OCDE (1987) & $1982-1984$ \\
\hline Suécia & Stiglbaurer et al. (2002) & $1987-1992$ & Taiwan & Tsou et al. (2002) & $1981-1994$ \\
\hline Taiwan & Tsou, Liu e Hammit (2001) & $1987-1997$ & Uruguai & Haltiwanger et al. (2004) & $1989-1995$ \\
\hline
\end{tabular}

Fonte: Elaboraçấo própria. 